\title{
Simulation of PaCKage Delivery OPTIMIZATION USING A COMBINATION OF CARRIERS AND DROP-SHIP
}

\author{
Valentyn M. Yanchuk, Andrii G. Tkachuk, Dmytro S. Antoniuk, \\ Tetiana A. Vakaliuk and Anna A. Humeniuk \\ Zhytomyr Polytechnic State University, Zhytomyr 10005, Ukraine
}

\begin{abstract}
A variety of goods and services in the contemporary world requires evolutionary improvement of services e-commerce platform performance and optimization of costs. Contemporary society is deeply integrated with delivery services, purchasing of goods and services online, that makes competition between service and good providers a key selection factor for end-user. As long as logistic, timely, and cost-effective delivery plays important part authors decided to analyse possible ways of improvements in the current field, especially for regions distantly located from popular distribution canters and drop-ship delivery networks. Considering both: fast and lazy delivery the factor of costs is playing an important role for each end-user. The work proposes a simulation that analyses the current cost of delivery for e-commerce orders in the context of delivery by the Supplier Fleet, World-Wide delivery service fleet, and possible vendor drop-ship and checks of the alternative ways can be used to minimize the costs. Special attention is given to Drop-Ship networks as the factor of possible costs decrease. The main object of investigation is focused around mid and small companies living far from big distribution canters, in the rural areas but actively using e-commerce solutions for their daily activities. The authors analysed and proposed a solution for the problem of cost optimization for packages delivery for long-distance deliveries using a combination of paths delivered by supplier fleets, worldwide, local carriers and drop-ship networks. Data models and Add-ons of contemporary Enterprise Resource Planning systems have been used, and additional development is proposed in the perspective of the flow selection change for combination of carriers. The experiment is based on data sources of the United States companies using a wide range of carriers for delivery services and uses the data sources of the real companies; however, it applies repetitive simulations to analyse variances in obtained solutions for different combinations of carriers.
\end{abstract}

\section{KEYWORDS}

Simulation, Customer Behavior, Drop-Ship, Optimization, E-commerce.

\section{INTRODUCTION}

\subsection{Formulation of the Problem}

It is very hard to imagine the contemporary world without planned deliveries, goods, and services ordered online or without scheduled charges for services, etc.

The delivery of e-commerce products has reached unexpected heights in the last few years. Most deliveries made with e-commerce consist of parcels, small packages, and food containers. Forrester Analytics builds the trends that the share of online retail will continue to grow steadily in the next years in the US [1]. Deliveries may have a variety of options like collection points, pickup locations, or direct delivery to the customer location. 
From the perspective of distribution policy, there are two main types of deliveries from the perspective of the full path and last-mile logistics:

Fast delivery (within the same day or next day early morning), where the deadline for delivery passes very fast;

Lazy delivery (optional days for delivery) when the customer has to adapt to specific delivery days which is not necessary the next day or not even the nearest day or the week. Some Lazy deliveries can deliver on Wednesdays or Mondays and Fridays depending on the capacity of the delivery provider.

It is rather hard to imagine the implementation of deliveries without Drop-Ship implementation of deliveries, where deliveries are implemented by an external party delivering goods on behalf of another vendor. This type of delivery is getting more and more popular in the world of eCommerce in the last decade.

So, the workload of the online shop team is entirely packed. Every day the web-shop or any other online service operational employee collects items for an order then carefully packs them and sends via delivery service to the end-users. The great ease of this brings the online rate shopping tools that can calculate the costs precisely. With the variety of different vendor's carriers and modes of delivery, the end-user may choose between cost speed and flexibility.

Business to Business (B2B) E-commerce solutions have even more carriers and delivery modes due to the fact they are making delivery of smaller and bigger parcels sometimes even renting the place in a big car so-called Less than Truck Load (LTL) or Greater than Truck Load GTL services. The Business to Consumer (B2C) segment has standardized.

The bigger portion of implemented deliveries are properly scheduled for deliveries, however, still, there is a part, which stays at depots, waiting for an occasion to be picked up. As an alternative - companies are searching for quicker drop-ship options from other vendors, making their orders in other regions. Such an alternative gives great flexibility for networks, that are not much afraid of competition and who may still support fair use policy.

In the market of the US, there are a lot of big players like FedEx, UPS, USPS, which makes the majority of deliveries for domestic, interstate, and international deliveries. All these carriers have web APIs that enable quick rate shopping for many e-commerce platforms [2]. At the same time, these big players are not picking bulky deliveries, which are greater than $65 \mathrm{~kg}$, which can be an issue for car parts deliveries, etc. All these constraints are less impacting when you have specified add-ons that use online services helping rate-shop any basket or order and give almost an immediate result with the delivery rate per several shipping options. Nowadays this becomes rather standard to use online APIs that help quicker rate-shop the customers' basket and indicate the price. For better and precise calculation, the basket composition should also keep the delivery address, which should be validated by the delivery service to guarantee the parcel delivery. Dimensional packaging (width $\times$ height $\times$ depth) are optional but more important for bigger deliveries, which may be reviewed in other manuscripts, due to the different nature of the study.

Let us have a quick look at how the customer understands the order delivery as in Figure 1:

- $\quad$ The order is being recorded in the system;

- $\quad$ The order is being packed;

- $\quad$ The order is got delivered to the location. 


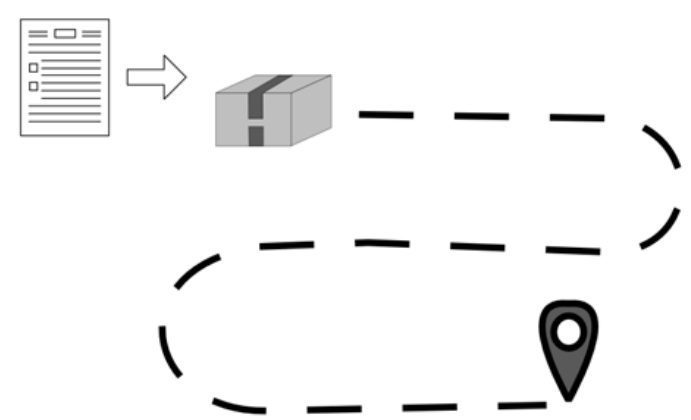

Figure. 1. The simplified scheme of how the client sees the order delivery process

However, the order delivery in the real life is fulfilled like in the below screen, representing way more participants of this process and intervals with different delivery transformations and the number of steps performed as in Figure 2.

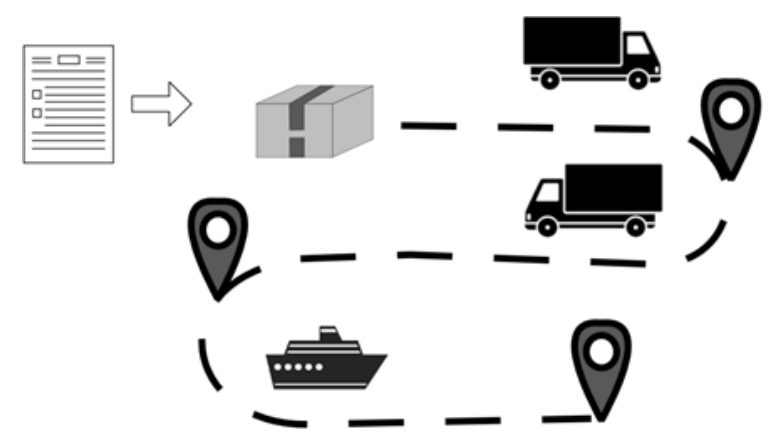

Figure. 2. The simplified scheme of how the client sees the order delivery process

Below is the simplified scheme of web-shop interaction with an online application integrated service, outlined by authors based on the online experience with the majority of online platforms.

(Step 1) the client forms basket at the online service.

(Step 2a) the basket is getting totals and tax calculated along with the total weight of the delivery (required).

(Step $2 \mathrm{~b}$ ) the dimensional information per product should be indicated per item for the possible use of packaging software calculating the costs for dimensional delivery (optional).

(Step 3) the Shipping origin (the depot or warehouse address) and Delivery address (in full, including Zip-code, city, state, country, Street, and Street 2 addresses should be provided (required).

(Step 4) Online API returns the calculated costs that can be added to the order total and prepared for payment with the full variety of methods and options for delivery.

(Step 5) Online ordering service forms the order for fulfilment and further this order is going for package. Some APIs provide reservation of the tracking number for the delivery, as long as this is finalized and will proceed to the carrier for delivery.

(Step 6) Delivery is scheduled, and the final delivery time is indicated to the client. 
There is specifically highlighted the delivery address and shipping origin address, as they are the key factor for delivery costs calculation and dictate the distance or zone of delivery that plays an important role for the carriers.

Step 3 is an important part of the e-commerce flow, as this information should be dully validated for proper calculation. Besides, the Delivery Address should be recognized by the carrier to validate if there is a delivery to that address. Besides, here is another problem in the investigation: the rural addresses are hardly recognized by carriers, even if they are fully registered addresses with appropriate geolocation. Most carriers are covering specific network locations and points of delivery where the API can calculate the costs. Even the phone call to the carrier does not help much if the operator is seeing the same situation in his system.

There are always debates around the rural delivery areas [3], far distant locations with limited delivery services [4] and the current research will not make the edge cases better, and however, the rural areas will certainly be considered. Unlike B2C, which is always dealing with different locations nowadays there are well-developed rural zones and distant locations, where many farmers, smaller businesses concentrate their main locations, as these locations real estate and the land is cheaper. However, this does not resolve the problem of delivery, which becomes more and more problematic.

Several works already considered this problem [5] and many times the authors tried to streamline the delivery paths and wanted to go beyond their possibilities. For re-sellers it is important to save on costs as much as possible and keep the very good service. One of the costs, where the reseller still loses is the transportation to the re-sellers' depots or packing points and then a calculation of the delivery should go further.

As known, the last-mile [6] delivery is currently regarded as one of the most expensive and least efficient portions of the entire supply chain.

This idea was observed in detail by Reyes and Taniguchi [7-8], based on the generalized vehicle routing problem (vendors' truck fleet in the given case) with time windows that have been explored. The study of Reyes, which also considered the earlier publications of urban and rural areas [9] proved that fleet of trucks type of delivery, could reduce total distances up to $40 \%$ for an application in the city of Atlanta. This research intends to build on the current state of the art by integrating the notion of travel time uncertainty.

Thus, one of the alternative solutions would be a Drop-ship implementation by the partner or subcontracting network, delivering orders, submitted at one network, validated via another network for availability with subsequent implementation of the order by partner or subcontracting network, as in Figure 3.

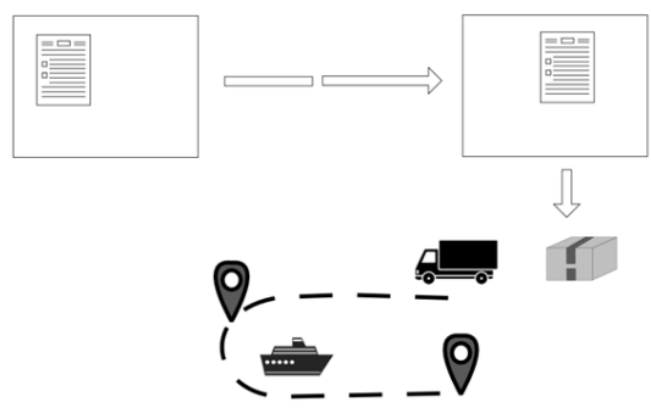

Figure. 3. The simplified scheme of how the client sees the order delivery process 
As a very simple and direct solution the fleet of trucks for vendors cruising around the United States and delivery items, but the costs for truck maintenance and payments for the use of the service increases annually.

For the drop-ship solution currently, the availability validation may be done in various ways like EDI interface or Punch-out implementation, which is quite popular in the eCommerce world.

\subsection{Analysis of Recent Research and Publications}

The solution proposed is aimed mainly to optimize the e-commerce processes, help vendors and customers to get their orders in the best and cost-effective way. These intentions are highlighted in various publications directed to technical, economical sciences and a great deal of them still lies in the aspect of logistics optimization as well as forecasts of the upcoming infrastructural changes.

To cover this multidisciplinary approach let us disclose the existing relationships between ecommerce investigations made for shipments deliveries [3], including domains of domestic deliveries [4], rural areas deliveries [6-8], customer purchasing habits [11], simulation of deliveries in e-commerce systems.

The authors highlighted the approach of integration of delivery [2] were combined with the ecommerce solution with API services provided at the existing market. Overlapping of that work with publications of Routhier (2013) and Morganti and Dablanc (2014) uncovered the city and outside city delivery approach covering the transportation perspective and possible ways of further optimizations in that domain. Authors constantly suggested considering the direct and combined approaches of using the transportation system to optimize the time of delivery, however, the time is not always leading to a cost-effective solution.

Uwe Clausen, Christian Geiger (2016) in their hands-on testing of the last mile concept tried to cover the problems of building the optimal logistic way for larger vehicles using creating the Urban Consolidation Centers. However, this covers only the part of approaches that contemporary e-commerce systems have to consider, and smaller and medium enterprises may not arrange such centers on their own. Besides the approaches reviewed for Europe are not always easily applicable to the US with the higher distances and wider distribution of centres.

Reichheld and Schefter (2000), Abrham et al. (2015), Zelazny (2017) or Ehrenberger et al. (2015) observe that there is a significant relationship between long-term growth of companies' profitability and customer purchase intention [13] however that indicated a good insight that analyzing mid-size companies and trace the turnover and orders circulation it will be easier to identify the dependencies between the options people usually chooses and possible shipment options the current vendors can offer.

For testing data generators many researchers applied Monte Carlo methods, among them, are Sakas, Vlachos, (2014) to create simulations when the mean and variances are known - for our research we can use it to easier generate the experimental data for the current research. The authors decided to apply the Monte Carlo method based on recent researches [14 - 15] described in this work as this suits best the nature of the research performed and reflects statistical inference regarding the original sampling domain. For the first step of the simulation, we have taken the original entries of orders accumulated in the test ERP and a very similar distribution will be generated with the Monte Carlo method. Comparison of Monte Carlo with the "what if" method gives better confidence intervals, that will give a better approximation. 


\section{The MeThOD}

In a simplified view, the conceptual framework of the interaction of the re-sellers' eCommerce solution with vendors and delivery networks can be presented as in Figure 4.

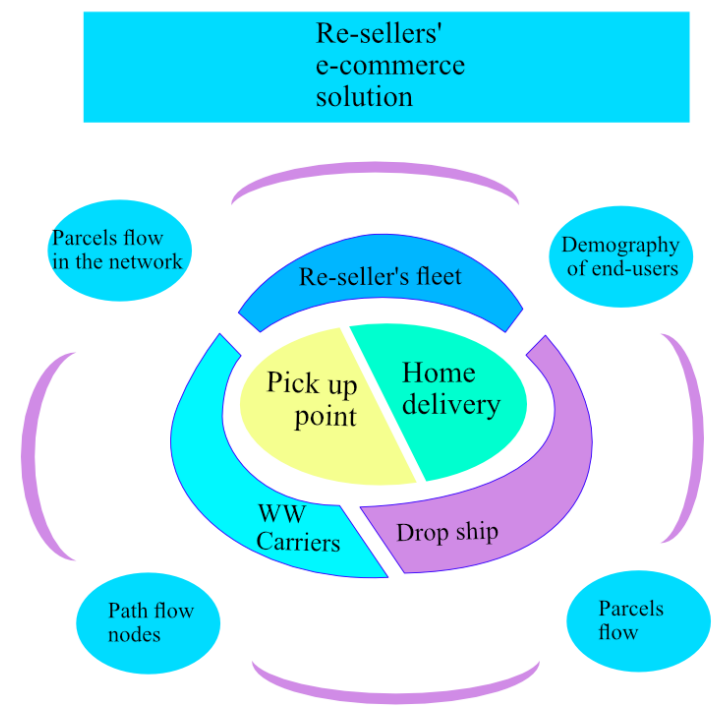

Figure. 4. The conceptual framework for a delivery network, from an operators' point of view. Adapted from [4]

So, in the current investigation, let us generate hundreds of orders based on real addresses of user form the Web-shop database and attempt to:

- Rate-shop those with World Wide Carriers (WW carriers) like UPS and FedEx with the basket compositions to export from sample shops.

- Select Pick-Up delivery from the nearest location (according to [10-11] it still gives a lot of benefits from an economic point of view).

- Use the truck fleet of the vendor for distant deliveries with the truck cost taken per ride.

- $\quad$ Use the Drop-Ship delivery from other networks.

Allocate an option to deliver via partner network, which will be the fleet of the supplier, which anyways deliver the parcels to the online sellers. Drop-ship service is also having costs, but these costs are covered with the Dealer Discount rate, which can be still considered as a benefit. For the given task and simplicity let us set up the discount on delivery costs to $5 \%$.

For a given investigation of the products selected is not that important, as at Step 2a important is the weight of the basket assembled. To mitigate the risk that clients will not be satisfied with generated basket fetching their order - authors filtered out orders that are having too high prices for delivery since that is obvious the customers may give up delivering them.

Dimensional values for products are not important, the focus is on the selection of the delivery per weights and the range of weight will be between 60 , which still falls into International deliveries and is already interested in LTL service providers and are both good for Own and Supplier's truck fleets. 
The same is applied for Drop-ship deliveries, as they are approaching the same channels as normal orders fulfilled by the companies, even though the delivery costs for other networks may be way less due to a better location.

For the experiment taken 4 US companies where the vendor provides the goods for re-seller, who sell the products to the customer. Having statistical information on these companies the authors can compare the results of simulations with orders that were found and compared in the system via scanning the database and comparing the costs incurred to date. The companies are selected in pares to investigate 2 fleets of re-sellers versus the fleet of vendors for delivery of drop-ship orders.

The analysis of the results will be presented in the context of how much costs the customer saves with the time window not more than 1 day longer than the vendor's truck fleet, which is a guaranteed way of delivery.

\section{RESULTS}

Using the Monte Carlo method there were generated $\mathrm{n}$ orders in 4 networks located in California and distributed across 4 networks S1, R2, R3, and S4 that have the following distribution of clients per with urban and rural zones and percentage of network with the distant rural zone (see the Table 1).

Table 1. Distribution of the network with rural and urban zones

\begin{tabular}{|c|c|c|c|c|c|}
\hline Netw & Classification & $\begin{array}{c}\text { Urban zone } \\
\text { clients }\end{array}$ & $\begin{array}{c}\text { Rural zone } \\
\text { clients }\end{array}$ & $\begin{array}{c}\text { Orders } \\
\text { generated for a } \\
\text { week }\end{array}$ & $\begin{array}{c}\text { \% of Rural } \\
\text { distant zone } \\
\text { orders }\end{array}$ \\
\hline S1 & Supplier of R2 & 210 & 380 & 1200 & 30 \\
\hline R2 & Re-seller of S1 and S4 & 250 & 320 & 1800 & 25 \\
\hline R3 & Re-seller of S4 & 200 & 180 & 1300 & 45 \\
\hline S4 & Supplier of R1 and R2 & 320 & 260 & 1500 & 26 \\
\hline
\end{tabular}

There is no overlapping of clients between networks; however, dependencies of Supplier and Reseller are given in the column Network Dependencies and orders distributions.

It has been performed 8 simulations (by 2 runs for each type of simulation to calculate the deviation) using Test Dynamics NAV (Enterprise Resource Planning system) custom developed add-on feeding the system with Delivery addresses of a given distribution of Rural Distant zone orders and called the Online and network services for the price calculation. A custom add-on is developed based on Retail Add-on that can trace the system of discounts and particularly evaluate the behavior of the customer. The ease of use of this Add-on got rid of behavioral model validation, as Retail Add-on collects the customer orders in the context of basket composition and the selected shipping method.

Method Monte-Carlo is used to check if the number of the rural distant zone is more than $10 \%$ deviation from setting up original parameters as recommended in [11].

The number of generated orders is controlled by several parameters, that specify the distribution canters, within the area. We are using the uniform distributions of orders around the average order. 
The locations of customers and network canters are fixed and they are failing into exponential distributions. In [15] authors also validated the traces using uniform distribution to simulate locations obeys the observed exponential distribution.

When the Monte-Carlo method was applied, the following distribution of the carriers was made across networks (see Table2).

A comparison of orders generated by the Monte-Carlo method is shown in the last column of the table.

Table 2. Distribution of the selection for Far rural zone

\begin{tabular}{|c|c|c|c|c|c|c|}
\hline Carriers & $\begin{array}{c}\text { Average price per order } \\
\text { with the same weight }\end{array}$ & S1 & $\mathbf{R 2}$ & $\mathbf{R 3}$ & $\mathbf{S 4}$ & \% of deviation \\
\hline FedEx & 120 USD & 219 & 73 & 41 & - & 12 \\
\hline Vendor Truck & 80 USD & 301 & 523 & 162 & 400 & 18 \\
\hline Supplier Truck & 75 USD & 490 & 18 & 212 & 5 & 20 \\
\hline PickUP location & 20 USD* & 130 & 186 & 395 & 265 & 38 \\
\hline Total & - & 1140 & 800 & 810 & 670 & - \\
\hline
\end{tabular}

*The price per pick-up appeared due to the fact of overdue for taking orders from location center

Including into simulation the factor of cancellation of pick-up locations (distributors may potentially cancel delivery to a specific location) and see how the average price impacts the customer if they keep selecting the rest of vendors. The first run shows that customers start selecting either Supplier truck or FedEx, especially if the weight combination comes closer to the FedEx edge weight of $60 \mathrm{~kg}$ (See Table 3).

Table 3. Second simulation results overview

\begin{tabular}{|c|c|c|c|c|c|c|}
\hline Carriers & $\begin{array}{c}\text { Average price per order with } \\
\text { the same weight }\end{array}$ & $\mathbf{S 1}$ & $\mathbf{R 2}$ & $\mathbf{R 3}$ & $\mathbf{S 4}$ & $\begin{array}{c}\text { \% of } \\
\text { deviation }\end{array}$ \\
\hline FedEx & 100 USD & 393 & 57 & 432 & 260 & 22 \\
\hline Vendor Truck & 80 USD & 17 & 48 & 65 & 24 & 18 \\
\hline Supplier Truck & 75 USD & 730 & 695 & 497 & 386 & 15 \\
\hline Total & - & 1140 & 800 & 810 & 670 & \\
\hline
\end{tabular}

Results were reviewed with the descent analysis of the simulation results and, due to the fact the ERP generation add-on is used, the dependency of the Vendor Truck, which delivers to the pickup location of Supplier organization, that chain was filtered.

To avoid gaps in the behavioral model it was decided to export data from Google Analytics Extended (supplied by Google Tag Manager) choice preferences versus a list of available vendors and repeat the simulation. It was found that the generation add-on is trying to mimic the webshop user's behavior in case of the absence of Pickup location following the tendency of the user's choice.

As an additional limitation, it was decided to exclude FedEx. At this moment of simulation, it became easier to trace that customers' orders became in the status of Dropped, as some users indeed were leaving web-shops not finding the guaranteed delivery provider. According to [12] the variety of delivery methods for the B2C segment should have a wider range of prices for delivery, then the choice of the customer will be either in favor or cheapest or most reliable carrier (personal user preference). However, B2B users in this simulation behaved exactly like 
B2C customers, preferring to abandon the basket or order and leave, rather than select the cheapest option. However, another tendency was noticed, that abandoned baskets were noticed from the users, who reached the limit of the price they are ready to pay; thus, the factor of the economy played an important role. The last attempt of simulation is taken with the assumption that the customer may use the Vendor's truck for the same price as the supplier, but the additional day may be added to the total route time (see Table IV).

Table 4. Forth simulation results overview

\begin{tabular}{|c|c|c|c|c|c|c|}
\hline Carriers & $\begin{array}{c}\text { Average price per order } \\
\text { with the same weight }\end{array}$ & S1 & $\mathbf{R 2}$ & $\mathbf{R 3}$ & $\mathbf{S 4}$ & $\begin{array}{c}\text { \% of } \\
\text { deviation }\end{array}$ \\
\hline Vendor Truck & 75 USD & 621 & 729 & 549 & 493 & 20 \\
\hline Supplier Truck & 75 USD & 519 & 71 & 261 & 177 & 22 \\
\hline Total & - & 1140 & 800 & 810 & 670 & \\
\hline
\end{tabular}

As it is seen from the results the clients behaved more reluctant to the delay in 1 day, however, they selected the home delivery via the Vendor's truck, rather than the supplier. I assume this happened due to the price change and most probably, no competence with the supplier appeared a key factor for Vendors' truck network. This also proves the statements described in [12] that users ordering bigger deliveries are usually more reluctant to have guaranteed delivery, rather than have it fast, but the tendency is equivalent for both: B2B and B2C segments as it is also indicated in [13].

Worth mentioning that $45 \%$ of Supplier Trucks were also implemented via Drop-Ship orders, which seriously lowered the costs for S4 in particular.

The current investigation is complete, however during the investigation, it was identified, that simulation of orders creation with the only ERP data without analytical data will only indicate the quantitative part, without the qualitative part that can be filled with additional statistical data per customer on personal preferences of choices in different cases of orders created in the live systems and presence or absence of the carrier in certain circumstances. Thus, adding Google Analytics Extended data on user choice allowed us to complete the investigation.

Google Analytics covered the validation of Users Acceptance Testing (UAT) and reflection of their behavior for generated orders. Additionally, the use of Google Analytics given an insight into the comparison of generated orders and directed to UAT for different groups of users during the application testing and run-down tests performed in all 4 companies selected.

Table 5, indicating the coverage of orders by comparison of generated orders and directed to UAT with orders recently submitted in the system (completed orders) will serve as the validation baseline for the approach suggested.

Table 5. Coverage of the real orders for Far rural zones* that correspond to generated orders per simulation

\begin{tabular}{|c|c|c|c|c|c|c|}
\hline Carriers & $\begin{array}{c}\text { Average price per order } \\
\text { with the same weight }\end{array}$ & $\mathbf{S 1 , \%}$ & $\mathbf{R 2 , \%}$ & $\mathbf{R 3 , \%}$ & $\mathbf{S 4 ,} \%$ & $\begin{array}{c}\text { \% of } \\
\text { deviation }\end{array}$ \\
\hline FedEx & 120 USD & 92 & 92 & 86 & 75 & 18 \\
\hline Vendor Truck & 80 USD & 90 & 87 & 95 & 65 & 20 \\
\hline Supplier Truck & 75 USD & 89 & 68 & 73 & 85 & 22 \\
\hline PickUP location & 20 USD* & 76 & 64 & 86 & 92 & 19 \\
\hline Average & - & 87.65 & 77.75 & 85 & 79.25 & 23 \\
\hline
\end{tabular}


* Far Rural zones are distantly located areas having lower delivery capacities, mostly implemented by private delivery networks and lower flows of international carriers, and $40 \%$ of them are implemented by Drop-Ship networks.

As we see, generated orders have rather high coverage from the data perspective and lie in the frame of deviations we calculated recently (Table 6.).

Table 6. Coverage of the real orders for Domestic zones that correspond to generated orders per simulation

\begin{tabular}{|c|c|c|c|c|c|c|}
\hline Carriers & $\begin{array}{c}\text { Average price per } \\
\text { order with the same } \\
\text { weight }\end{array}$ & $\mathbf{S 1 , \%}$ & $\mathbf{R 2 , \%}$ & $\mathbf{R 3 , \%}$ & $\mathbf{S 4 , ~ \%}$ & $\begin{array}{c}\text { \% of } \\
\text { deviation }\end{array}$ \\
\hline FedEx & 120 USD & 97 & 92 & 95 & 97 & 15 \\
\hline Vendor Truck & 80 USD & 90 & 92 & 90 & 96 & 17 \\
\hline Supplier Truck & 75 USD & 95 & 88 & 89 & 87 & 16 \\
\hline PickUP location & 20 USD* & 90 & 89 & 86 & 92 & 20 \\
\hline Average & - & 93 & 90.25 & 90 & 93 & 21 \\
\hline
\end{tabular}

A higher level of coverage for orders generated for domestic zones is relatively easy to explain from the perspective of a higher number of orders generated for domestic zones.

\section{Conclusions}

The series of simulations performed given a possibility to evaluate the behavior of users in case of absence of usual carriers and taking the decision of cheaper solution It also demonstrates options the web-shop owner may offer to the mid and small-size businesses alternative delivery services, where the drop-ship of vendor delivers to the final destination or drop-point with minimal costs if the additional discount is given to keep the order fulfillment. As a continuation of this work can be developed and on-line web-service to support delivery network visualizing deliveries of vendors and re-sellers, where all packages can be loaded into the truck, correct the route, and deliver goods and services with Vendor's fleet, as long as the route and discount permits.

To apply the current solution to the real industrial case will involve the expansion of the Vendor and Re-seller networks sharing the same data model for orders and street validation. In the case of contemporary ERP systems use that should not be a very difficult problem, however, it may involve additional 3-rd party services.

Introduction of the Drop-Ship orders into the scheme seriously decreased the costs of delivery, which may be recommended to industries, especially where delivery costs are significant.

The paper highlighted the combination of approaches of drop-ship deliveries and selection of different routes for total costs optimization and indicated that the behavior of the client is not always driven by economic circumstances, but also by habits and tendencies of customers, so well described in [7].

For future investigations, authors will involve Google Tag Manager data, collected for customers, as the import of options for checkout selection helped discover how customers may potentially abandon basket if they do not see the option of the habitual carrier or the price for the order versus delivery cost exceeds a specific limit. 


\section{REFERENCES}

[1] Forrester Analytics (2018). Forrester Online Retail Forecast, 2018 to 2023 (US).

[2] Yanchuk V. Gumenyuk A., Tkachuk A integrated add-ons for shipment providers and their connection to the e-commerce solution - Proceedings of II International scientific-practical conference "Computer technologies: innovations, problems, and solutions". - Zhytomyr, - 2017, 17 18

[3] Routhier, J. L. (2013). French cities' urban freight surveys. City logistics research: A transatlantic perspective. Conference proceedings 50 Summary of the First EU-US Transportation Research Symposium. (pp.9-14). Washington, DC: Transportation Research Board of the National Academies. doi:10.1108/IJPDLM-01-2016-0008

[4] Morganti, E., Dablanc, L., Fortin, F., 2014. Final deliveries for online shopping: The deployment of pickup point networks in urban and suburban areas. Research in Transportation Business \& Management, 11, 23-31. doi: 10.1016/j.rtbm.2014.03.002

[5] Motte-Baumvol, B., et al. / Asian Transport Studies, 4(3) (2017). doi: 10.11175/eastsats.4.585

[6] Song, L., Cherrett, T., McLeod, F., Wei, G., 2009. Addressing the last mile problem. Transport impacts of collection and delivery points. Transportation Research Record: Journal of the Transportation Research Board, 2097, 9-18. doi: 10.3141/2097-02

[7] Reyes, D., Savelsbergh, M., Toriello, A., "Vehicle routing with roaming delivery locations," Transp. Res. Part C Emerg. Technol., vol. 80, pp. 71-91, 2017. doi: 10.1016/j.trc.2017.04.003

[8] Visser, J., Nemoto, T., \& Browne, M. (2013). Home delivery and the Impacts on urban freight transport: A review. Urban areas recent advances in city logistics: Proceedings of the VII international conference on city logistics, Bali, Indonesia, June 17-19 (pp. 14-31). doi: 10.1016/j.sbspro.2014.01.1452

[9] E. Taniguchi, R.G. Thompson, T. Yamada, ed by E. Taniguchi, T. Fang Fwa and R.G Thompson (CRC Press, 2014), p. 1

[10] Weltevreden, J.W, 2008. B2c e-commerce logistics: the rise of collection-and-delivery points in The Netherlands. International Journal of Retail \& Distribution Management, 36, 8, 638- 660. doi: $10.1108 / 09590550810883487$

[11] Schewel, L., \& Schipper, L. (2012). Shop 'till we drop: A historical and political analysis of retail goods movement in the United States. Environmental Sciences Technology, 46-18, 9813-9821. doi: $10.1021 / \mathrm{es} 301960 \mathrm{f}$

[12] Accenture (2015). Adding Value to Parcel Delivery. www.accenture.com Accessed on 9 Jan 2017.

[13] Roudposhti, V.M., Nilashi, M., Mardani, A., Streimikiene, D., Samad, S., \& Ibrahim, O. (2018). A new model for customer purchase

[14] The intention of e-commerce recommendation agents. Journal of International Studies, 11(4), 237253. Doi:10.14254/2071-8330.2018/11-4/17

[15] J. Zheng et al./Computers and Geotechnics $67 \quad$ (2015) $103-109$. doi.org/10.1016/j.compgeo.2015.02.016

\section{AUTHORS}

Valentyn Yanchuk, Associate Professor at the Department of Automation and Computer-Integrated Technologies named after Prof. B.B. Samotokin, Zhytomyr Polytechnic State University, Zhytomyr, Ukraine

Valentyn Yanchuk, born in 1975, received a Candidate of Technical Sciences degree (Ph.D.) from the Pukhov Institute for Modelling in Energy Engineering, National Academy of Sciences of Ukraine (IMPE) in 2002. Since 1997, he has been working in the field of Software Engineering and Information Technologies at the Zhytomyr Polytechnic State University, where he is currently working at the position of Associate Professor and in the practical field of IT business. His research interests include software engineering, business analysis, computer-based modeling, ECommerce. He has published several papers and proceedings in the journals and

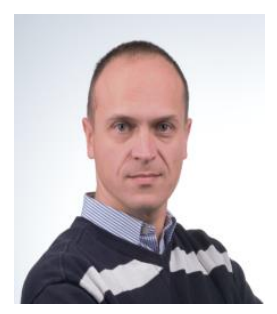
material of conferences. 
Assoc. Prof. Andrii Tkachuk, Head of the Department of Automation and Computer-Integrated Technologies named after prof. B.B. Samotokin, Zhytomyr Polytechnic State University, Zhytomyr, Ukraine.

Andrii Tkachuk, born in 1989, received a Candidate of Technical Sciences degree from the National Technical University of Ukraine "Kyiv Polytechnic Institute", Ukraine, in 2014. Since 2012, he has been working in the field of information technologies, automation, and robotics at the Zhytomyr Polytechnic State University. Andrii Tkachuk is an Expert of the Scientific Council of the Ministry of Education and Science of Ukraine, a Board member of NGO "Youth integration center". His research interests include information technologies, automated aviation gravimetric systems, mobile robotics, armament stabilization systems. He has published several papers in international journals, is a reviewer of The scientific journal Aviation which is included in the Scopus database.

Dmytro Antoniuk, Assistant Professor of the Department of Software Engineering, Zhytomyr Polytechnic State University, Zhytomyr, Ukraine

Dmytro Antoniuk, born in 1981, received a Candidate of Pedagogical Sciences degree (Ph.D.) from the Institute of Information Technologies and Learning Tools, Ukraine, in 2018. Since 2003, he has been working in the field of Software Engineering and Information Technologies at the Zhytomyr Polytechnic State University, where he is currently an Assistant Professor of the Department of Software Engineering and in the practical field of IT business. His research interests include software engineering, business in IT, computer-based business-simulation, economic and financial literacy of technical professionals. He has published several papers and proceedings in the

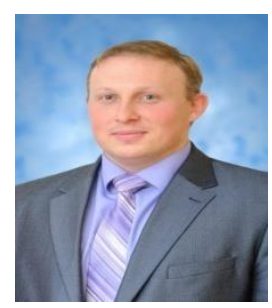
journals and material of conferences.

Dr. Tetiana Vakaliuk, professor of the Department of Software Engineering, Zhytomyr Polytechnic State University, Zhytomyr, Ukraine.

Tetiana Vakaliuk, born in 1983, received a Candidate of Pedagogical Sciences degree from the National Pedagogical Dragomanov University, Ukraine, in 2013, and a Doctor of Pedagogical Sciences degree from the Institute of Information Technologies and Learning Tools of the National Academy of Sciences of Ukraine, in 2019. Since 2019, she has been working in the field of information technologies at the Zhytomyr Polytechnic State University. Her research interests include information technologies, ICT in Education, Cloud technologies. She has published several papers in international journals, is a member of editorial boards of Information Technologies

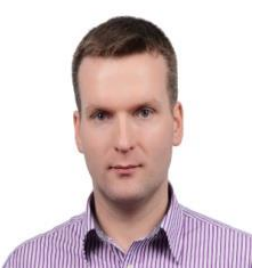
and Learning Tools, Zhytomyr Ivan Franko State University Journal: Pedagogical Sciences, Collection of Scientific Papers of Uman State Pedagogical University.

Anna Humeniuk Associate Professor at the Department of Automation and Computer-Integrated Technologies named after Prof. B.B. Samotokin, Zhytomyr Polytechnic State University, Zhytomyr, Ukraine

Anna Humeniuk, born in 1986, received a Candidate of Technical Sciences degree (Ph.D.) from the National Technical University of Ukraine "Igor Sikorsky Kyiv Polytechnic Institute" in 2011. Her scientific interests include automated measuring

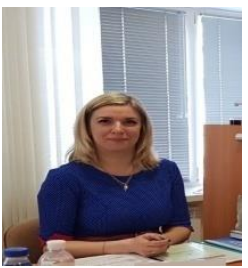
systems, gravimetry, flexible manufacturing system design automation. She has published several papers and proceedings in the journals and material of conferences. 